\title{
Spatial epidemiology of bovine leptospirosis in Veracruz, Mexico
}

\author{
Rigo Gutiérrez-Molina ${ }^{1}$, Pelayo Acevedo ${ }^{2}$, Sokani Sánchez-Montes ${ }^{3}$, Dora Romero-Salas ${ }^{1}$, \\ Argel Flores Primo ${ }^{1}$, and Anabel Cruz-Romero ${ }^{1}$ \\ ${ }^{1}$ Universidad Veracruzana, Facultad de Medicina Veterinaria y Zootecnia \\ ${ }^{2}$ Instituto de Investigación en Recursos Cinegéticos \\ ${ }^{3}$ Universidad Nacional Autonoma de Mexico Facultad de Medicina
}

November 1, 2020

\begin{abstract}
Bovine leptospirosis is a bacterial disease that affects bovine herds, causing economic losses due to reproductive problems, which require expensive treatments. The main source of transmission for cattle is still uncertain, but it has been described that small wild mammals can play an important role in the transmission cycle by being maintenance hosts for the pathogenic species of the bacterium and spreading it through urine. In this study, we characterize possible risk areas for bovine leptospirosis in the state of Veracruz, Mexico; based on the geographical distribution of small wild hosts of Leptospira sp. reported in Mexico in addition with climatic, geographic, land use and human activities variables, and validated risk map with bovine seroprevalence data. We used a generalized linear regression model to understand the association between the appearance of bovine leptospirosis seroprevalences and the favorability of wild hosts of Leptospira sp. as well as environmental variables. The parameterized model explains $13.58 \%$ of the variance. The seroprevalence in cattle showed a negative relationship with elevation, geographic length and human population density, and a positive relationship with environmental favorability for the bats reservoirs and favorability for at least one rodent and opossum reservoir. The variation in seroprevalence is mainly explained by a longitudinal gradient ( $10.4 \%$ of the variance) and the favourability for bats (3.0\% of the variance). Describing the possible risks of seroprevalence in an important and neglected livestock geographical region, we contribute to the selection of areas of strategies for diagnosis and prevention of this relevant disease.
\end{abstract}

\section{Hosted file}

(Guti\selectlanguage\{ngerman\}érrez-Molina et al.) Spatial epidemiology-PY.pdf available at https://authorea.com/users/372000/articles/490161-spatial-epidemiology-of-bovineleptospirosis-in-veracruz-mexico 


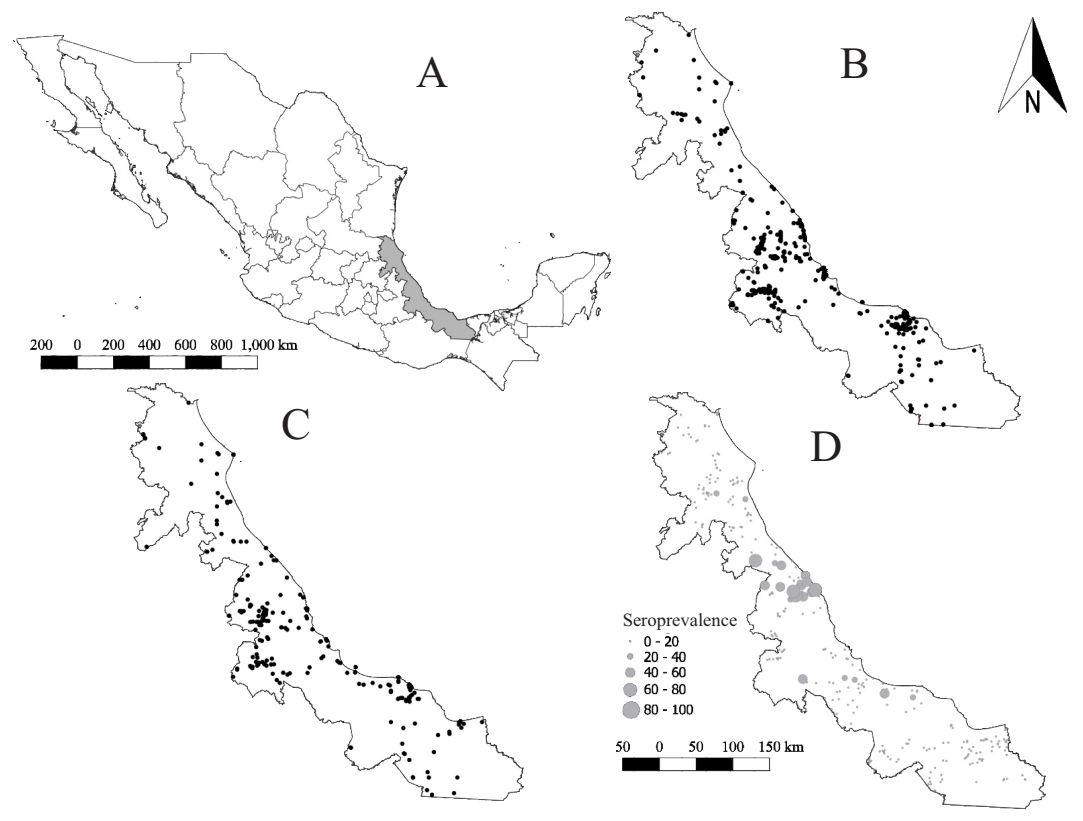

2 

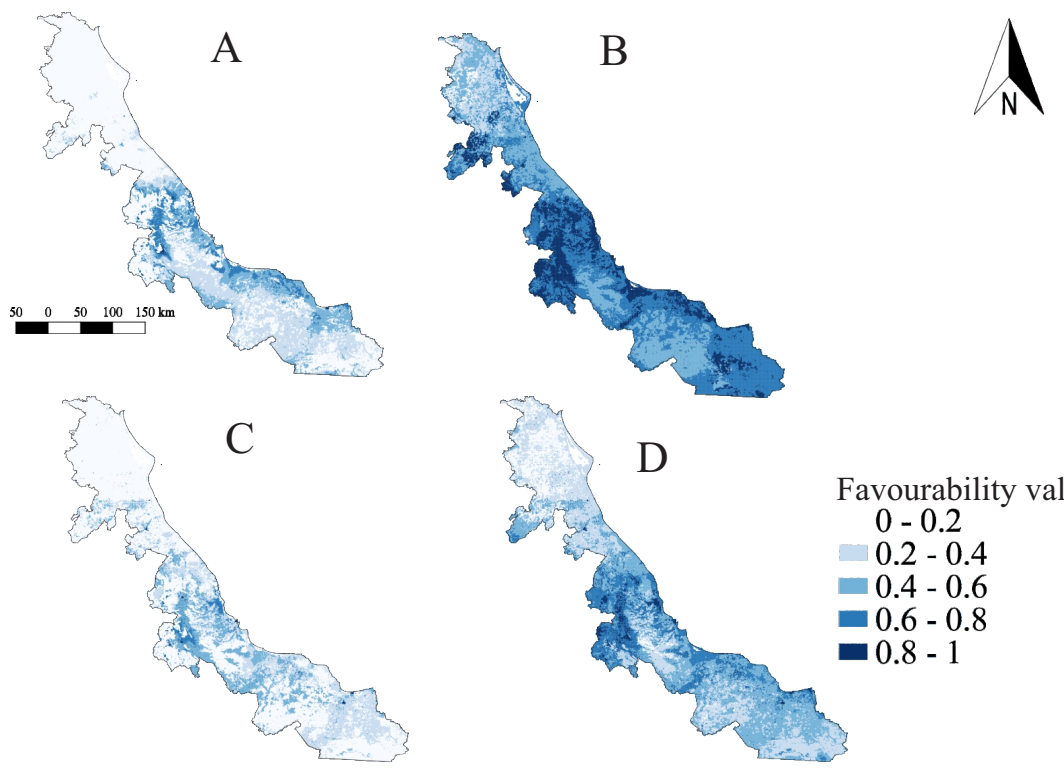

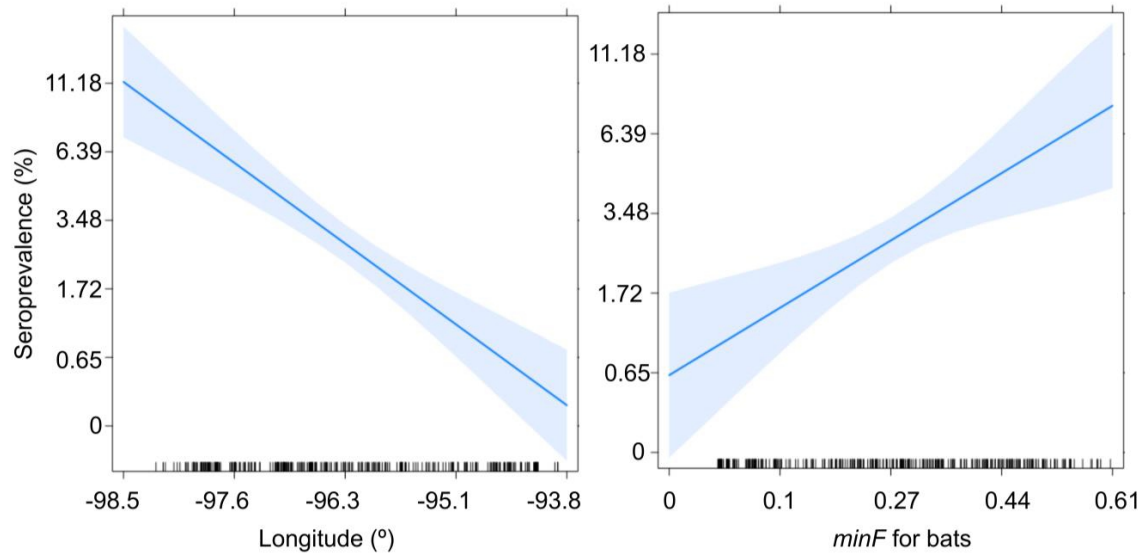


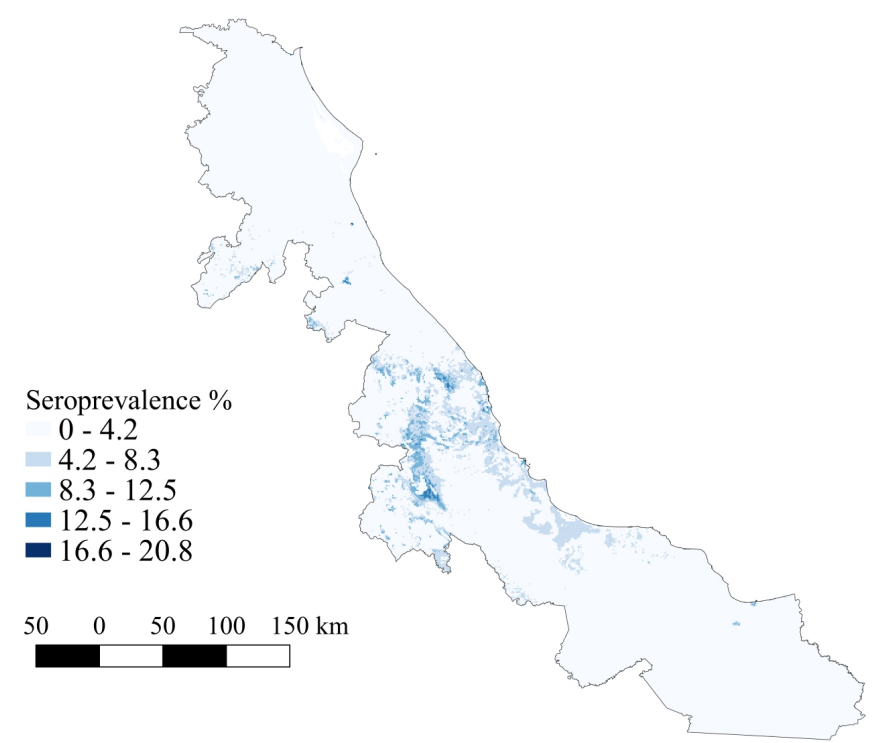


Bat species
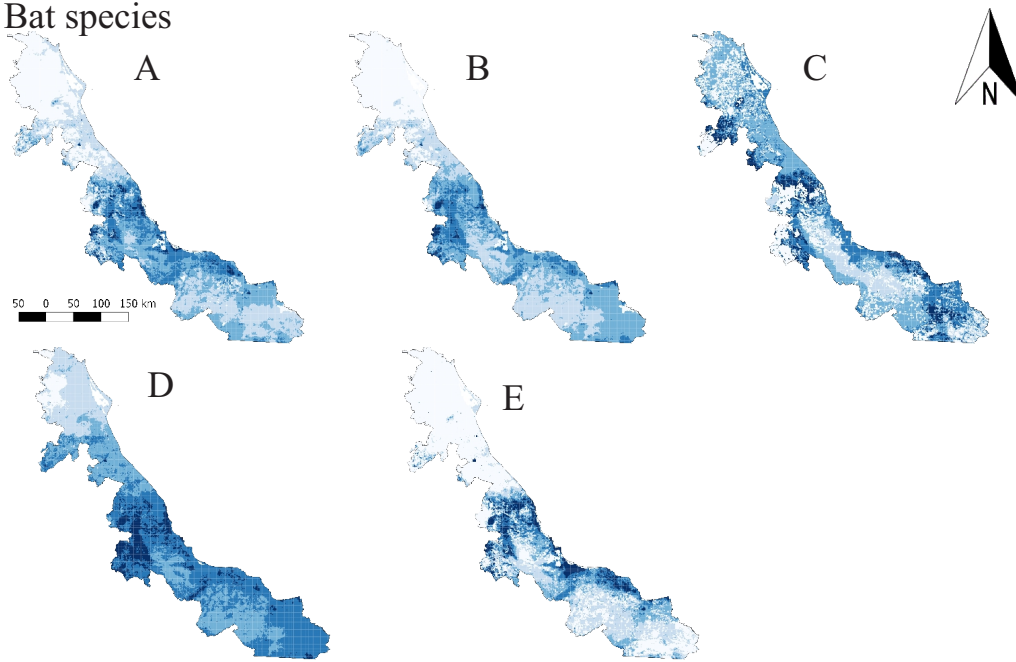

Rodent species
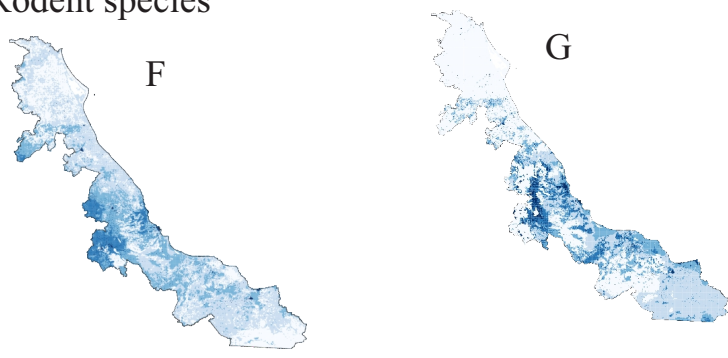

Opossum species
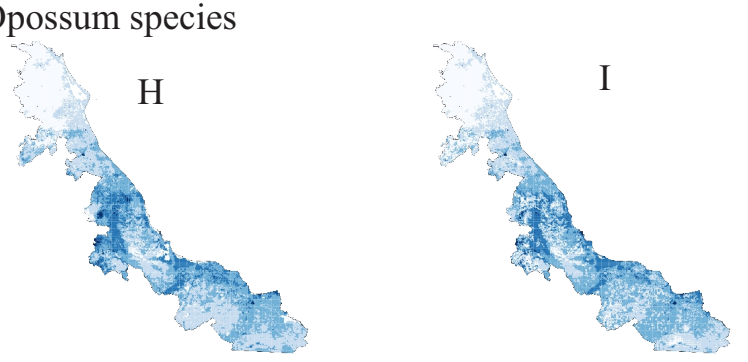

Favourability values

$0-0.2$

$0.2-0.4$

$0.4-0.6$

$0.6-0.8$

- $0.8-1$ 
Bats
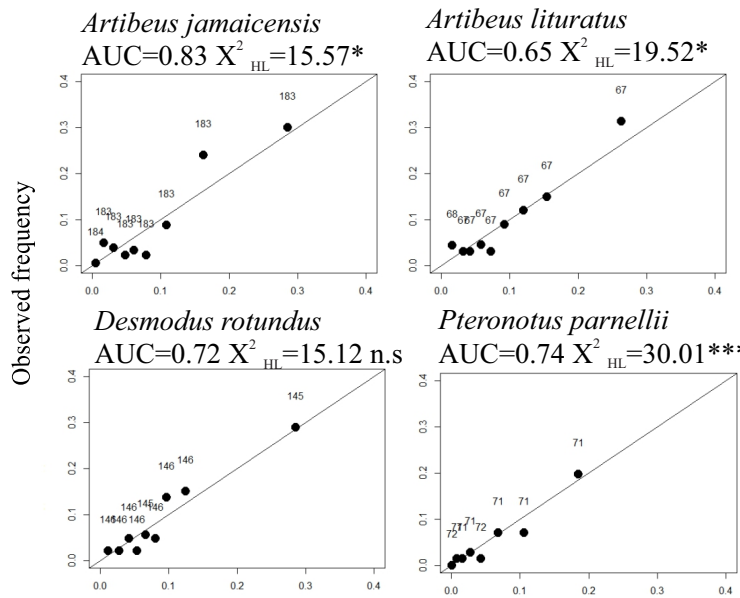

Chiroderma villosum

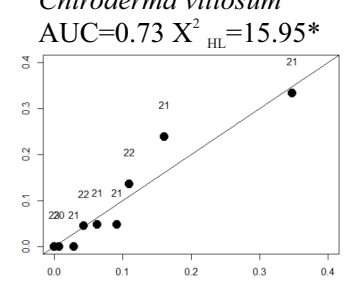

Rodents
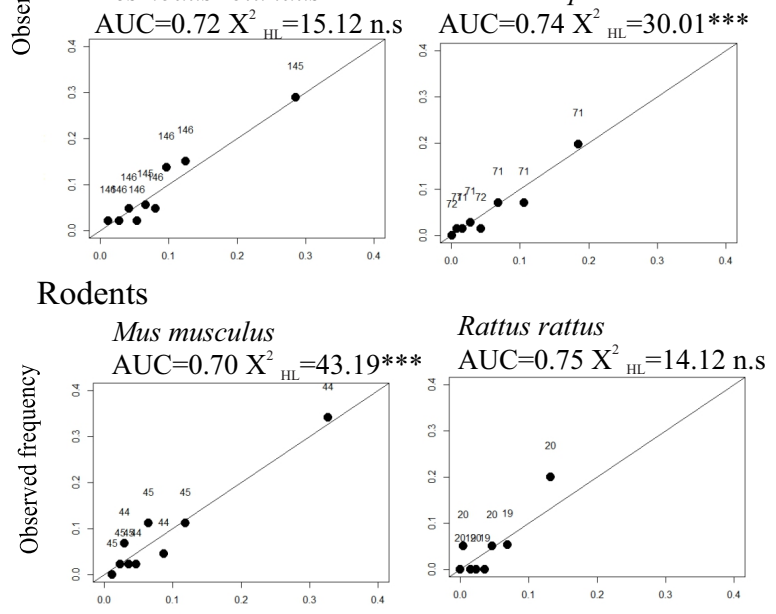

Opossums

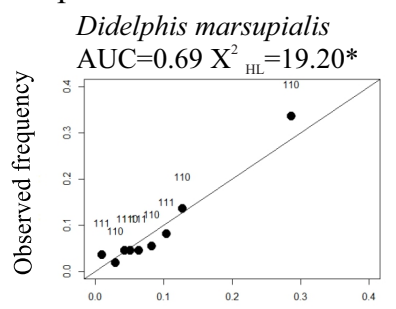

Didelphis virginiana $\mathrm{AUC}=0.69 \mathrm{X}_{\mathrm{HL}}^{2}=31.51 * * *$

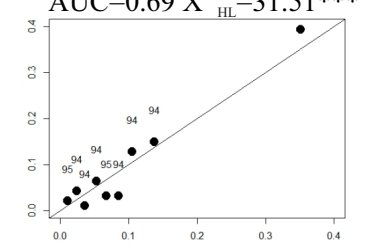

